\title{
Comparative Analysis on Treatment of Fluoride Containing Solution Using Novel Activated Carbon Prepared from Lemon Shell and Wheat Bran:Batch and Column Studies
}

\author{
Swapnila Roy* and Papita Das \\ Department of Chemical Engineering, Jadavpur University, Kolkata, India \\ Email: swapnilaroy@gmail.com
}

\begin{abstract}
The present study focused on de-fluoridation of waste water using thermally activated bio-sorbents prepared from Lemon Shell [LS] and Wheat Bran [WB]. Adsorption efficiency of the synthesized activated carbon was analyzed using batch and column study. Batch studies using both the adsorbent were carried out at different experimental condition to achieve the optimum condition for removal of fluoride present in water. The fluoride uptake capacity of the adsorbent was fitted to Langmuir and Freundlich isotherm model and it was observed that Langmuir model can better represent the experimental results. The Thomas model and the BDST model were used for continuous column studied and it was observed that both model can represented the experimental results. The optimum dose, contact time and temperature were found to be $1.0 \mathrm{~g} / 100 \mathrm{~mL}, 70 \mathrm{~min}, 343$ $\mathrm{K}$ respectively for lemon shell activated carbon and $2.0 \mathrm{~g} / 100 \mathrm{~mL}, 60 \mathrm{~min}, 343 \mathrm{~K}$ respectively for wheat bran activated carbon.
\end{abstract}

Keywords: Fluoride, adsorption, Activated carbon, lemon shell, wheat bran, isotherm, kinetics.

\section{Introduction}

Fluorine is a naturally available element that does not exist in the elemental state in nature. As it is more reactive, so it exists in the form of fluorides in various minerals such as fluorspar, cryolite and fluorapatite[1]. Inorganic fluorine compounds are used in industry for different purposes such as ceramic, nanotechnology industries. Usually fluorosilicic acid, sodium hexafluorosilicate and sodium fluoride are used in water fluoridation. Fluoride concentrations in water resource (surface water and ground water) depends on several contributing factors, such as $\mathrm{pH}$, total dissolved solids, alkalinity, hardness and geochemical composition of aquifers. The concentration of fluoride in groundwater varies according to various factors such as the depth at which the water is found and the quantity of fluoride bearing minerals in that area. Studies of literature revealed that daily fluoride uptake widely varied according to the various sources of exposure. As elevation of fluoride intake in drinking water [2] is significantly higher, so after oral uptake, water-soluble fluorides are almost absorbed in the gastrointestinal tract and then it is transported through the blood in human body. As the transportation capacity of fluoride is very fast in human body, it can be accumulated into teeth, bones and skeletal tissues. Fluoride intake can affect skeletal tissues gradually. If fluoride concentration in drinking water increases up to $3 \mathrm{mg} / \mathrm{L}$, then skeletal fluorosis may occur. Different studies of literature revealed that drinking water is the major source of fluoride intake and continuous consumption of drinking water with heightened fluoride concentrations can induces birth, reproduction and immunological defects, dental and skeletal fluorosis[3]. Increasing fluoride exposure on animal may result of osteosarcomas on animal. Fluoride exposure can result bladder cancer, mainly among workers who are exposed to it. The toxicological effect of fluoride on human health and environment drives urgent need to find out an effective method for the removal of excess fluoride from drinking water. According to the national standards $[4,5]$ it is essential to consider the uptake of fluoridated water from food and air.

The present study is highlighted on the preparation of activated carbon [AC] from lemon shell and wheat bran [6] as an adsorbent and its application for the treatment of fluoride containing wastewater. Various process parameters such as effect of adsorbent dose, contact time, reaction temperature were 
experimented to study the effect of these parameters on the removal efficiency. Optimization of the process parameters has been performed to achieve the better removal capacity of the both AC. The adsorption isotherm and adsorption capacity of AC (LS and WB) in batch and column studies were also investigated.

\section{$2 \quad$ Materials and Methods}

\subsection{Preparation of Adsorbents}

The raw material used for preparation of activated carbon was lemon shell and wheat bran. These were the precursor for preparation of activated carbon. These two raw materials were collected from local area of Kolkata, India. Firstly, both materials were washed several times with distilled water to remove surface impurities and then dried at $378 \mathrm{~K}$. Then the dried material was grinded, activated using phosphoric acid followed by carbonization in muffle furnace. The complete carbonization occurred at 723 $\mathrm{K}$. Then it was cooled to room temperature and washed with distilled water until their $\mathrm{pH}$ equal to 7 which indicated absence of any acid. Then the sample were dried, cooled and stored in an air-tight container for further study.

\subsection{Physicochemical properties of activated carbon}

The different physicochemical properties[7,8,9] such as yield of carbon, bulk density, porosity, moisture content, ash content and $\mathrm{pH}$ of the prepared activated carbons were estimated using standard procedures [10,11]. All the experiments were performed thrice and the average value had been considered.

\subsubsection{Yield of Carbon}

After carbonization the resulting activated carbon was weighed. The percentage yield of carbonizing is achieved by applying this equation:

$$
\% \text { yield of carbon }=\frac{\text { weight of char }}{\text { weight of raw material }}
$$

\subsubsection{Determination of Bulk Density}

The dry empty $10 \mathrm{ml}$ centrifuge tube was cleaned and weighed (W1) and then the centrifuge tube was filled with the prepared activated carbon powder and weighed (W2). The difference in the weights denotes the weight of the activated carbon powder in tube. The bulk density was estimated using the following equation:

$$
\text { Bulk Density }=\frac{\mathrm{W} 2-\mathrm{W} 1}{\text { volume of centrifuge tube }}
$$

\subsubsection{Porosity Determination}

The porosity of the activated carbon was estimated using the formula:

$$
\text { Porosity }=\frac{\text { pore volume }}{\text { total volume }}
$$

The pore volume of prepared activated carbon was achieved using the formula:

$$
\text { Pore volume }=\frac{\text { Bulk density of activated carbon }}{\text { density of water }}
$$

Hence,

$$
\text { porosity }=\frac{\text { Bulk density of activated carbon }}{\text { density of water X Total volume }}
$$

\subsubsection{Determination of Moisture Content}

The empty crucible was dried at $110^{\circ} \mathrm{C}$ and then cooled in a desiccator and weighed (W1). Then the prepared known weight of activated carbon powder with crucible were weighed (W2) and dried in an oven at $110^{\circ} \mathrm{C}$. This weight was taken constantly at $30 \mathrm{~min}$ interval until the weight became constant. 
Then activated carbon with crucible was cooled in a desiccator and reweighed (W3). The weight difference of the activated carbon is used to measure the moisture content $\left(X_{0}\right)$ of the activated carbon prepared from lemon shell and wheat bran. The experimental error range for determining moisture content was within $\pm 2 \%$.

$$
X_{0}=\frac{W 2-W 3}{W 2-W 1} \times 100
$$

\subsubsection{Determination of ash content}

The empty crucible was oven dried at $110^{\circ} \mathrm{C}$ and cooled in a desiccator and weighed (W1). The known weight of prepared dried activated carbon powder was put the crucible and weighed (W2) and then kept in the muffle furnace at $800^{\circ} \mathrm{C}$ for 1 hour and then allowed to cool .Finally the crucible was reweighed (W3). The experimental error range for determining ash content was within $\pm 2 \%$. The percentage ash content of activated carbon sample was obtained from the following equation:

$$
\operatorname{Ash} \%=\frac{W_{a s h}}{W_{0}} \times 100=\frac{W 3-W 1}{W 2-W 1} \times 100
$$

Where $W_{a s h}=$ weight of ash $(\mathrm{g})$

\subsubsection{Determination of $\mathrm{pH}$}

$1 \mathrm{~g}$ activated carbon from lemon shell and wheat bran was weighed separately. Then it was dissolved in 3 $\mathrm{ml}$ distilled water. The mixture was heated and stirred for few minutes. Then it was filtered and $\mathrm{pH}$ was determined using a digital $\mathrm{pH}$ meter.

\subsubsection{Boehm Titration}

The surface acidity and basicity of the samples were estimated by the Boehm Titration method $0.2 \mathrm{~g}$ AC sample from lemon shell and wheat bran were added to $25 \mathrm{ml}$ of $0.1 \mathrm{M} \mathrm{NaHCO}_{3}$ and similarly to 25 $\mathrm{ml}$ of $0.1 \mathrm{M} \mathrm{Na}_{2} \mathrm{CO}_{3}$. The mixtures were stirred for 24 hours and then it was filtered. After removal of carbon, the excess of base and acid was titrated with $0.1 \mathrm{M} \mathrm{HCl}$ solution and $0.1 \mathrm{M} \mathrm{NaOH}$ solution, respectively. Chemically number of acidic sites was estimated by chemical neutralization of carboxyl, phenolic and lactonic groups by $\mathrm{NaOH}$; carboxyl and lactonic groups by $\mathrm{Na}_{2} \mathrm{CO}_{3}$; and carboxyl groups by $\mathrm{NaHCO}_{3}$. Similarly, the number of basic sites was estimated from the amount of consumed hydrochloric acid by AC.

\section{$3 \quad$ Experimental Set up}

\subsection{Batch experiments}

For batch experiments, $100 \mathrm{ml}$ fluoride containing solutions of concentration $50 \mathrm{mgL}^{-1}$ were taken in 250 mL PTFE (Polytetrafluoroethylene) conical flasks. The particular weighed amount of adsorbent (AC from lemon shell and wheat bran) were added to each solution. Then the flasks were agitated at 150 rpm in an incubator shaker (INNOVA 4430, New Brunswick Scientific, Canada) at different temperatures. After incubation for particular time intervals, samples were collected from the flasks and analysed The remaining fluoride solution after adsorption in each conical flask was estimated using ionmeter (Thermo Scientific Orion ion-meter, USA). The effects of contact time (10-100 min), adsorbent dose $(0.2-1.5 \mathrm{~g} / 100 \mathrm{ml})$ and temperature $(293 \mathrm{~K}-353 \mathrm{~K})$ were evaluated during the batch studies.

\subsection{Thermodynamic and Kinetic Studies}

\subsubsection{Adsorption Isotherm}

The isotherm models, Langmuir and Freundlich isotherms models were investigated by using AC-LS and AC-WB.The interaction between fluoride ions and adsorbents can be better explained by these two isotherm models.

\section{- Langmuir Isotherm}

The linear form of Langmuir model is given by the following equation: 


$$
\frac{C_{e}}{Q_{e}}=\frac{1}{Q_{0} b}+\frac{C_{e}}{Q_{0}}
$$

where $C_{e}$ is the residual fluoride concentration at equilibrium, $Q_{e}$ is the fluoride concentration adsorbed on the sorbent at equilibrium, $Q_{o}$ denotes maximum fluoride concentration and $b$ is the Langmuir constant.

\section{- Freundlich Isotherm:}

The Freundlich isotherm constants are estimated using the following equation:

$$
\ln Q_{e}=\ln K_{F}+\left(\frac{1}{n}\right) \ln C_{e}
$$

where $Q_{e}$ is the amount of fluoride adsorbed at equilibrium, and $K_{F}$ and $n$ are Freundlich constants indicates adsorption capacity and adsorption intensity respectively.

\subsubsection{Adsorption Kinetics}

The adsorption process was carried out at various temperature to determine the optimum temperature for maximum adsorption efficiency and for obtaining the reaction rate constant and activation energy.

\section{- Pseudo First order kinetics}

The first order rate constant is estimated using the following equation:

$$
\frac{d q_{t}}{d t}=k_{1}\left(q_{e}-q_{t}\right)
$$

where $q_{e}=$ fluoride adsorbed at equilibrium/unit weight of adsorbent $(\mathrm{mg} / \mathrm{g}), q_{t}$ is the amount of fluoride adsorbed at any instant $(\mathrm{mg} / \mathrm{g})$ and $k_{1}$ is the rate constant $\left(\mathrm{min}^{-1}\right)$.

Integrating at these conditions as $t=0$ and $q_{t}=0$ to $t=t$ and $q_{t}=q_{t}$, the final equation is written as given below:

$$
\log \left(q_{e}-q_{t}\right)=\log q_{e}-\frac{k_{1} t}{2.303}
$$

- Pseudo Second order kinetics

The pseudo second order equation is described as follows:

$$
\frac{t}{q_{t}}=\frac{1}{k_{2} q_{e} 2}+1 / q_{e}(t)
$$

where $k_{2}$ denotes the pseudo-second-order rate constant of adsorption $\left(\mathrm{g} \mathrm{mg}^{-1} \mathrm{~min}^{-1}\right)$ and $q_{e}$ and $q_{t}$ are the amounts of fluoride adsorbed $(\mathrm{mg} / \mathrm{g})$ at equilibrium and at time $t$ respectively.

\section{- Activation Energy}

From the obtained the rate constant, activation energy of the adsorption of fluoride is calculated using Arrhenius Equation (13) given as follows:

$$
\ln k_{2}=\ln A_{0} \frac{E_{a}}{R T}
$$

where $E_{a}=$ activation energy $\left(\mathrm{kJmol}^{-1}\right) ; R=\operatorname{gas} \operatorname{constant}\left(8.314 \mathrm{~J} \mathrm{~mol}^{-1} \mathrm{~K}^{-1}\right)$; and $A_{0}=$ Arrhenius constant.

\subsubsection{Adsorption thermodynamics:}

The adsorption thermodynamic parameters of fluoride are estimated using the following formulas:

$$
K_{c}=\frac{C_{a}}{C_{e}}
$$

where, $K_{c}=$ coefficient of distribution for the adsorption; $C_{a}=$ fluoride adsorbed per unit mass of the adsorbent $\left(\mathrm{mg} \mathrm{L}^{-1}\right) ; C_{e}=$ equilibrium concentration of adsorbate in aqueous phase $\left.(\mathrm{mg} \mathrm{L})^{-1}\right)$.

$$
\Delta G_{0}=-R T \ln K_{c}
$$

where $G_{0}\left(\mathrm{~kJ} \mathrm{~mol}^{-1}\right)=$ change of Gibb's free energy; $R=$ universal gas constant; and $T=$ absolute temperature $(\mathrm{K})$; and

$$
\ln K_{c}=\frac{\Delta S_{0}}{R}-\frac{\Delta H_{0}}{R T}
$$

where $\Delta H_{0}\left(\mathrm{~kJ} \mathrm{~mol}^{-1}\right)=$ change of enthalpy; $\Delta S_{0}\left(\mathrm{~J} \mathrm{~mol}^{-1} \mathrm{~K}^{-1}\right)=$ change of entropy. 


\subsection{Continuous Fixed-bed Adsorption Studies}

Continuous flow adsorption experiments $[12,13]$ were performed in a PTFE burette $(2.5 \mathrm{~cm}$ internal diameter and $10 \mathrm{~cm}$ height) at room temperature. A known quantity of the adsorbent was packed into that column. A cotton wool was attached at the bottom of the column to support the bed and also to ensure uniform inlet flow and proper liquid distribution into the column.

Fluoride solution of known concentration $\left(50 \mathrm{mg} \mathrm{L}^{-1}\right.$ )was poured in the PTFE burette. The effect of

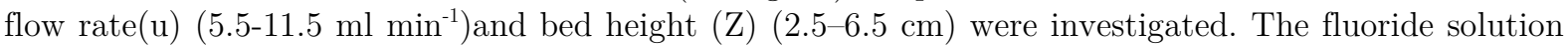
at the outlet of the column was collected at regular time intervals and the concentration of fluoride in the effluent was analyzed using Orion ion meter. This experiment was stopped until input fluoride concentration is equal to final fluoride concentration.

\subsubsection{Modeling of Column Data}

In this experiment, the bed depth service time (BDST) model and Thomas model were well fitted to the dynamic flow experimental data $[14,15]$ of fluoride adsorption in order to determine the characteristic parameters of the column.

$$
\begin{gathered}
\text { BDST: } \frac{N_{0}}{C_{0} F} Z-\frac{1}{K_{a} C_{0}} \ln \left(\frac{C_{0}}{C_{t}}-1\right) \\
\text { Thomas: } \ln \left(\frac{C_{0}}{C_{t}}-1\right)=\frac{k_{T h} q_{0} m}{F}-k_{T h} C_{0} t_{e}
\end{gathered}
$$

Where $N_{0}$ is the maximum volumetric sorption capacity $\left(\mathrm{mg} \mathrm{L}^{-1}\right), Z$ is the bed height $(\mathrm{cm}), C_{0}$ is the initial fluoride concentration $\left(\mathrm{mg} \mathrm{L}^{-1}\right), C_{t}$ is the concentration of fluoride at time $t\left(\mathrm{mg} \mathrm{L}^{-1}\right), u$ is the flow rate $\left(\mathrm{ml} \mathrm{min}^{-1}\right), K_{a}$ is adsorption rate constant $\left(\mathrm{L} \mathrm{mg} \mathrm{min}^{-1}\right), k_{T h}$ is the Thomas rate constant (ml $\left.\mathrm{mg}^{-1} \mathrm{~min}^{-1}\right), q_{0}$ is the equilibrium adsorbate uptake $\left(\mathrm{mg} \mathrm{g}^{-1}\right), \mathrm{m}$ is the mass of the adsorbent in the column $(\mathrm{g}), F$ is the volumetric flow rate $\left(\mathrm{ml} \mathrm{min}^{-1}\right)$ and $t_{e}$ is the bed exhaustion time (min).

\section{$4 \quad$ Results and Discussion}

\subsection{Characterization of Activated Carbon from Lemon shell and Wheat bran}

Table1. Physicochemical Analysis

\begin{tabular}{ccccccc}
\hline $\begin{array}{c}\text { Name of } \\
\text { Sample }\end{array}$ & $\begin{array}{c}\text { Yield of carbon } \\
(\%)\end{array}$ & $\begin{array}{c}\text { Bulk } \\
\text { Density }\end{array}$ & Porosity & $\begin{array}{c}\text { Moisture } \\
\text { content }\end{array}$ & $\begin{array}{c}\text { Ash } \\
\text { content }\end{array}$ & pH \\
\hline (1) AC-LS & 78 & 0.78 & 0.73 & 5.4 & 13.5 & 7.01 \\
$(2)$ AC-WB & 81 & 0.82 & 0.71 & 6.3 & 13.2 & 6.98 \\
\hline
\end{tabular}

- This trend in porosity indicated that the better correlation with the ash contents of the adsorbents and suggested that the acid leaching processes remove fine mineral matters from the adsorbents and result in formation of micropores, Here the difference in porosity between AC-LS and AC-WB were not so remarkable. So pore properties were very similar with each other.

- The trend in moisture content and bulk density indicated that there were not so remarkable difference in these two properties which proved that both adsorbents were dried and existed as powdered form with proper bulk density.

- The aqueous solution of both adsorbent was neutral in nature.

It was observed that the surface property of AC-LS and AC-WB were totally acidic. The total surface acidic groups, carboxyl groups, lactonic groups, phenolic groups in AC-LS were higher than the corresponding parameters in AC-WB, proved that the difference in surface chemistry between AC-LS and $\mathrm{AC}-\mathrm{WB}$ resulting from the different preparation of the carbonaceous materials. It also implied that the $\mathrm{HNO}_{3}$ oxidation clearly increased the surface acidic groups (carboxylic, lactonic, and phenolic groups) and decreased the basic groups of AC-LS. It may be concluded that the incomprehensive information, 
instead of total surface information, of oxygen-containing groups of $\mathrm{AC}$ can be discovered by results analyses of Boehm titration due to ability of the titration to detect qualitatively and quantitatively only some surface acidic groups (carboxylic, lactonic, and phenolic groups) and the basic groups.

Table2. Acidic and basic surface characteristics of the activated carbons

\begin{tabular}{|c|c|c|c|c|c|}
\hline \multirow{2}{*}{$\begin{array}{l}\text { Name of } \\
\text { Sample }\end{array}$} & \multicolumn{3}{|c|}{ Groups } & \multirow{2}{*}{$\begin{array}{l}\text { Total acidity } \\
\qquad\left(\mathrm{meq} \mathrm{g}^{-1}\right)\end{array}$} & \multirow{2}{*}{$\begin{array}{l}\text { Total basicity } \\
\quad\left(\operatorname{meq} \mathrm{g}^{-1}\right)\end{array}$} \\
\hline & $\begin{array}{c}\text { Carboxylic } \\
\left(\text { meq g }{ }^{-1)}\right.\end{array}$ & $\begin{array}{l}\text { Phenolic } \\
\left(\mathrm{meq} \mathrm{g}^{-1}\right)\end{array}$ & $\begin{array}{l}\text { Lactonic } \\
\left(\mathrm{meq} \mathrm{g}^{-1}\right)\end{array}$ & & \\
\hline AC-LS & 0.28 & 0.29 & 0.29 & 0.94 & 0.89 \\
\hline AC-WB & 0.23 & 0.27 & 0.26 & 0.9 & 0.85 \\
\hline
\end{tabular}

\subsection{Batch Studies}

\subsubsection{Effect of Adsorbent dose}

From experimental results it was observed (Fig. 1) that prepared activated carbon from wheat bran acted as a better adsorbent than activated carbon prepared from lemon shell for the treatment of fluoride containing solution. Within the experimental range of adsorbent dose in between $0.2 \mathrm{~g}-2.5 \mathrm{~g} / 100$ $\mathrm{ml}$, percent removal of fluoride gradually increases with increasing adsorbent dose, then decreases. It was observed that as he adsorbent dose (AC from LS and WB) increased from $0.2 \mathrm{~g} / 100 \mathrm{ml}$ to $2.5 \mathrm{~g} / 100$ $\mathrm{ml}$, de-fluoridation efficiency increased because of the availability of active sites on the adsorbent surface increases in both cases, but as the adsorbent dose higher than $1.0 \mathrm{~g} / 100 \mathrm{ml}$ for LS and $2.0 \mathrm{~g} / 100 \mathrm{ml}$ for WB, adsorption decreased because surface of adsorbent reached the saturation point by fluoride ions, hence fluoride ions were not adsorbed on adsorbent surface.

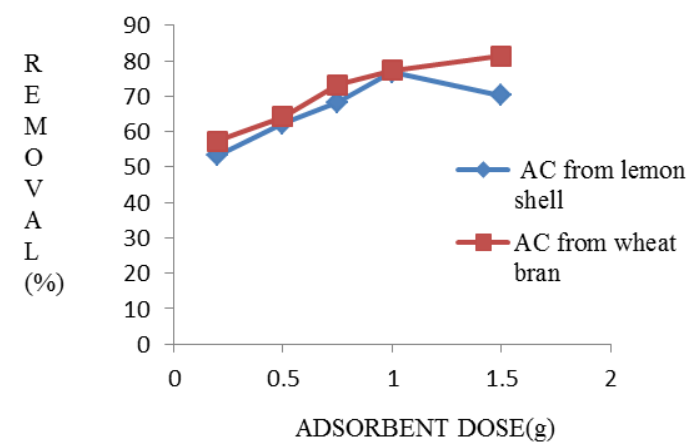

Figure1. Effect of adsorbent dose on removal of fluoride by AC-LS and AC-WB

\subsubsection{Effect of Contact time}

From Fig. 2 it was observed that activated carbon prepared from WB was much better adsorbent than activated carbon from LS for de-fluoridation in water. It was observed from the experimental study that on increasing the contact time at particular temperature, de-fluoridation efficiency increased in both cases. As the contact time increased, large number of fluoride ions was attached on the adsorbent surface. It can be explained that accumulation of fluoride ions on adsorbent surface increased because of attraction force in between adsorbent surface and fluoride ion, resulting increasing of fluoride removal present in solution. But after certain time (70 $\mathrm{min}$ for LS, $60 \mathrm{~min}$ for WB), de-fluoridation efficiency decreased. The reason may be that saturation of active site of the adsorbent occurred when reaction time reached to $60 \mathrm{~min}$ or $70 \mathrm{~min}$ (as mentioned above). After that no significant increase of adsorption was observed. So the optimized contact time was $70 \mathrm{~min}$ for AC-LS and $60 \mathrm{~min}$ for AC-WB. 


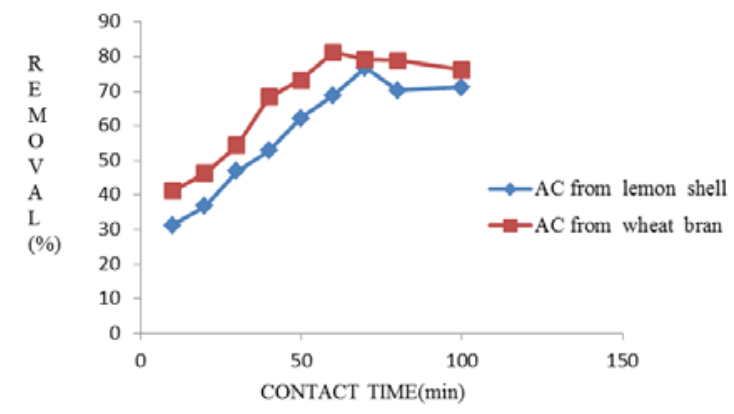

Figure2. Effect of contact time on removal of fluoride by AC-LS and AC-WB

\subsubsection{Effect of Temperature}

It was observed from the experimental study (Fig. 3) that with increasing temperature, the percent removal of fluoride first increased ( $293 \mathrm{~K}$ to $343 \mathrm{~K})$ and then decreased as temperature increased charge density of fluoride ions increased, the repulsive force increased between adsorbate and adsorbent surface and as a result the de-fluoridation efficiency gradually increased with increasing temperature. But as temperature increased beyond $343 \mathrm{~K}$, fluoride ion may desorbed from the surface of the activated carbon and so the removal efficiency of fluoride may decreased.

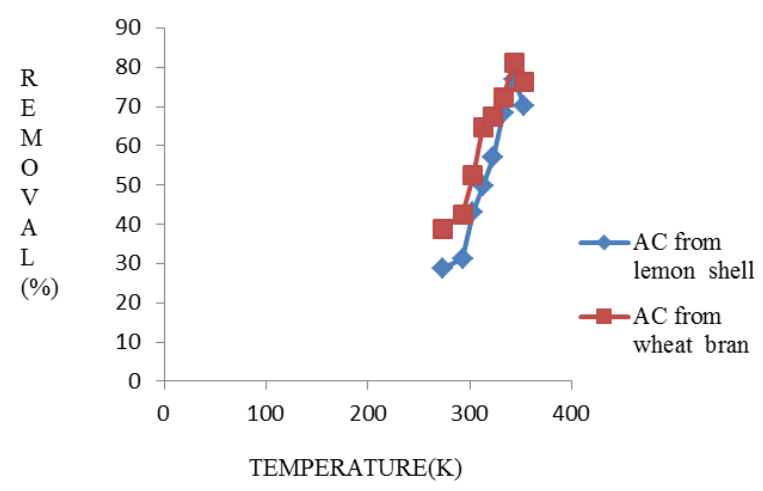

Figure3. Effect of temperature on removal of fluoride by AC-LS and AC-WB

\subsection{Batch adsorption isotherm}

The estimated adsorption equilibrium data for AC-LS and AC-WB was applied to Langmuir (Fig. 4A,4B) and Freundlich isotherms (Fig. 5A,5B) model. Using these two models the possible interaction between fluoride ions and prepared adsorbents could be well understood. The isotherm parameters were shown in Table 3. From Table 3, it was observed that Langmuir model was well fitted for both the adsorbents than Freundlich model[16] for the present study. According to the Langmuir model [17] the monolayer fluoride adsorption took place in each case and so the process was dependent on the surface homogeneity. 


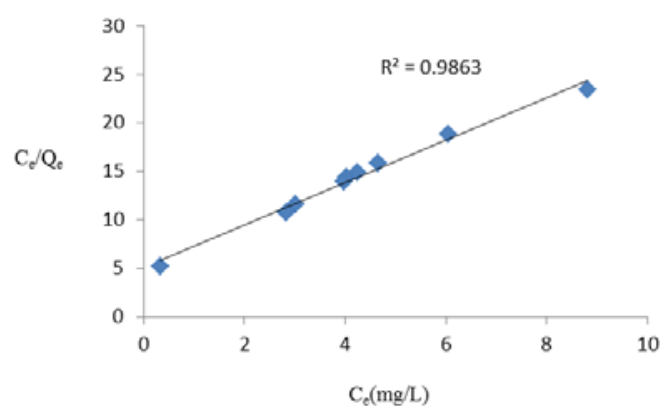

Figure4A. Langmuir Adsorption Isotherm plots of de-fluoridation onto AC-LS

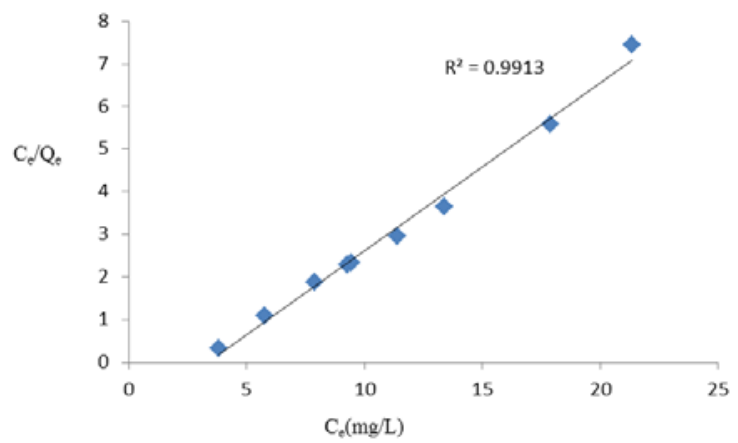

Figure4B. Langmuir Adsorption Isotherm plots of defluoridation onto AC-WB

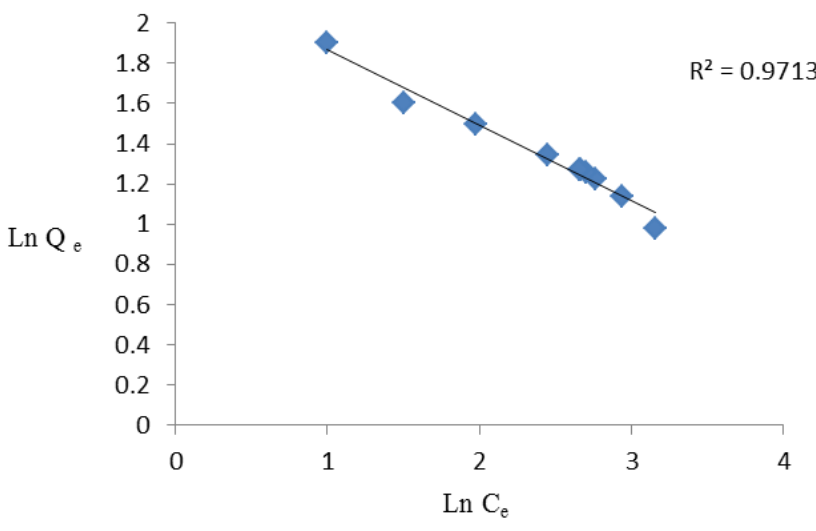

Figure5A. Freundlich Isotherm plots of defluoridation onto AC-LS

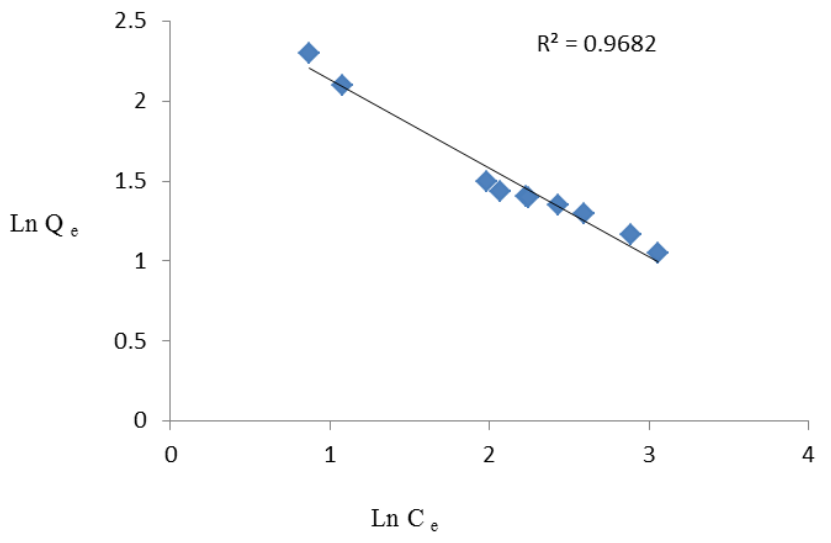

Figure5B. Freundlich Isotherm plots of defluoridation onto AC-WB

Table3. Langmuir and Freundlich isotherm model constants and correlation coefficients for fluoride adsorption onto AC-LS and AC-WB at optimized conditions

\begin{tabular}{cccc|ccc}
\hline \multirow{2}{*}{ Adsorbents } & \multicolumn{3}{c|}{ Langmuir } & \multicolumn{3}{c}{ Freundlic } \\
\cline { 2 - 7 } & $\mathbf{Q}_{\mathrm{e}}\left(\mathbf{m g ~ g}^{-1}\right)$ & $\mathbf{b}\left(\mathbf{L ~ m g}^{-1}\right)$ & $\mathbf{R}^{2}$ & $\mathbf{K}_{\mathrm{F}}\left(\mathbf{m g ~ g}^{-1}\right)$ & $\mathbf{n}\left(\mathbf{L ~ m g}^{-1}\right)$ & $\mathbf{R}^{\mathbf{2}}$ \\
\hline (1)AC-LS & 34.17 & 0.354 & 0.9863 & 56.54 & 4.23 & 0.9713 \\
(2)AC-WB & 41.23 & 0.621 & 0.9913 & 49.23 & 3.79 & 0.9682 \\
\hline
\end{tabular}

\subsection{Batch kinetics and Temperature}

The kinetics studies [18] were investigated in case of AC-LS and AC-WB for de-fluoridation techniques. The parameters of kinetic studies were shown in Table 4. From this study, it was observed that pseudo second order kinetics study was well fitted than pseudo first order rate expression. From the pseudo second order kinetic study, it was indicated that adsorption capacity of both adsorbent were dependent on available binding site. The plot of $t / q_{t}$ Vs $t$ (Fig. 6) of pseudo second order kinetic modeling were depicted. At $343 \mathrm{~K}$ the rate constant were $0.14 \mathrm{~g} \mathrm{mg}^{-1} \mathrm{~min}^{-1}$ and $0.176 \mathrm{~g} \mathrm{mg}^{-1} \mathrm{~min}^{-1}$ for AC-LS and ACWB respectively. Consequently from the experimentally obtained results it was proved that as the temperature increased from $293 \mathrm{~K}$ to $343 \mathrm{~K}$, the amount of adsorbed fluoride increased in both cases. This phenomena occurred due to increase in mobility of fluoride ions with temperature, as a result adsorption capacity also increased with temperature. From the pseudo second order rate constant $\mathrm{k}_{2}$ at 
different temperatures, the activation energy $\mathrm{E}_{\mathrm{a}}$ was estimated using the Arrhenius Equation (Eq. 13). The slope calculated from Arrhenius Equation were $32.87 \mathrm{~kJ} / \mathrm{mol}$ and $38.79 \mathrm{~kJ} / \mathrm{mol}$ for AC-LS and AC-WB respectively. From batch experimental studies it was observed that as the time increases the removal efficiency of fluoride increases as well as adsorption capacity and after a certain time $76.83 \%$ and $81.21 \%$ removal of fluoride were obtained for AC-LS and AC-WB respectively. At $343 \mathrm{~K} \mathrm{t} / \mathrm{q}_{\mathrm{t}} \mathrm{Vs} \mathrm{t}$ (Fig.6) showing linear plot with regression coefficient 0.9628 and 0.9758 for AC-LS and AC-WB respectively. At this temperature $(343 \mathrm{~K})$ the initial adsorption rate were $2.87 \mathrm{mg} \mathrm{g}^{-1} \mathrm{~min}^{-1}$ and $3.57 \mathrm{mg}$ $\mathrm{g}^{-1} \mathrm{~min}^{-1}$ for AC-LS and AC-WB respectively. This phenomena proved that AC-WB can be better adsorbent than AC-LS for effectively used for fluoride removal in batch experiment.

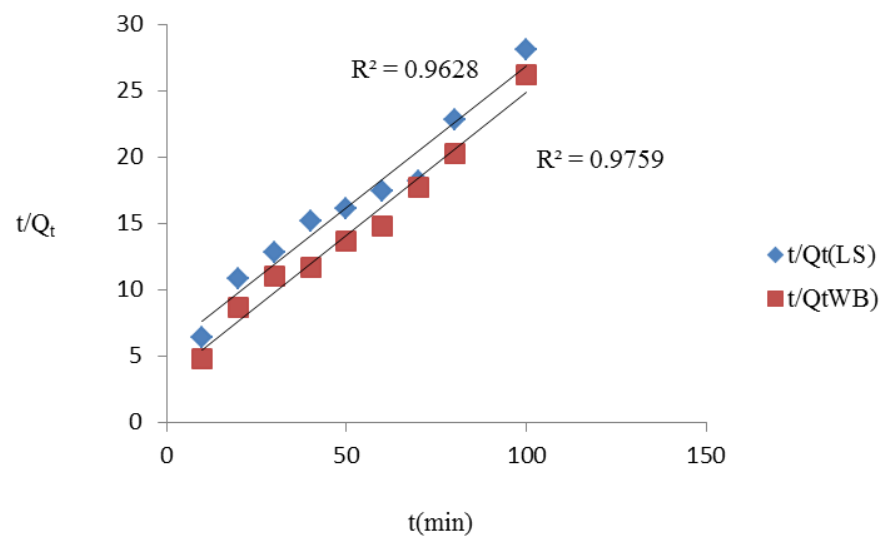

Figure6. Pseudo second order kinetic model for adsorption of fluoride by AC-LS and AC-WB

Table4. Comparison of pseudo first order and pseudo second order rate constants for AC-LS and AC-WB at optimized conditions

\begin{tabular}{cccc|crc}
\hline \multirow{2}{*}{ Adsorbents } & \multicolumn{2}{c|}{ Pseudo first order kinetics } & \multicolumn{3}{c}{ Pseudo second order kinetics } \\
\cline { 2 - 7 } & $\mathbf{k}_{\mathbf{1}}(\mathbf{m i n})$ & $\mathbf{q}_{\mathbf{e}}\left(\mathbf{m g} \mathbf{~ g}^{-\mathbf{1}}\right)$ & $\mathbf{R}^{\mathbf{2}}$ & $\mathbf{k}_{\mathbf{2}}\left(\mathbf{g ~ m g}^{-1}\right)$ & $\mathbf{q}_{\mathbf{e}}\left(\mathbf{m g ~ g}^{-\mathbf{1}}\right)$ & $\mathbf{R}^{\mathbf{2}}$ \\
\hline (1)AC-LS & 0.0033 & 39.21 & 0.9537 & 0.0521 & 26.72 & 0.9628 \\
(2)AC-WB & 0.00011 & 59.21 & 0.9611 & 0.0782 & 38.79 & 0.9759 \\
\hline
\end{tabular}

\subsection{Estimation of thermodynamic parameters of both activated carbon for de- fluoridation}

From the experimental data following equation(14-16) it was observed that the value of $\Delta \mathrm{G}^{0}$ increased with increasing temperature (up to 343K) indicating that the adsorption was thermodynamically[19] feasible in nature and the positive values of $\Delta \mathrm{H}^{0}$ supported endothermic nature of the reaction due to consuming energy from the reaction system. The values of $\Delta \mathrm{H}^{0}$ and, $\Delta \mathrm{S}^{0}$ were estimated from the slopes and intercept of the plot $\ln K_{c}$ vs. $(1 / T)$ (Fig. not given) and the values were listed in Table 5 . It was observed that the negative value of $\Delta G^{0}$ at all temperatures represented that the de-fluoridation reaction was spontaneous in nature. In this case $\Delta G^{0}$ decreased up to $343 \mathrm{~K}$ and after that it increased which implies that the adsorption was spontaneous up to $343 \mathrm{~K}$. As a result the randomness in between fluoride ion and activated carbon surface was increased. Due to endothermic reaction, it may be expected that the uptake capacity of fluoride ions by activated carbon increased with temperature. 
Table5. Thermodynamic parameters for the adsorption of fluoride onto AC-LS and AC-WB

\begin{tabular}{|c|c|c|c|c|c|c|c|}
\hline \multirow{2}{*}{ Serial No. } & \multirow{2}{*}{$\mathbf{T}, \mathbf{K}$} & \multicolumn{2}{|c|}{$\Delta \mathrm{G}^{0}, \mathrm{~kJ} / \mathrm{mol}$} & \multicolumn{2}{|c|}{$\Delta \mathrm{H}^{0}, \mathrm{~kJ} / \mathrm{mol}$} & \multicolumn{2}{|c|}{$\Delta \mathrm{S}^{0}, \mathrm{~J} \mathrm{~mol}^{-1} \mathrm{~K}^{-1}$} \\
\hline & & AC-LS & AC-WB & AC-LS & AC-WB & AC-LS & AC-WB \\
\hline 1 & 293 & -8.93 & -9.83 & & & & \\
\hline 2 & 313 & -10.23 & -11.93 & & & & \\
\hline 3 & 333 & -12.45 & -13.94 & 62.33 & 72.19 & 252.11 & 267.39 \\
\hline 4 & 343 & -13.32 & -14.29 & & & & \\
\hline 5 & 353 & -11.45 & -12.56 & & & & \\
\hline
\end{tabular}

\subsection{Column Studies}

In order to evaluate the effectiveness of AC-LS and AC-WB for continuous mode fluoride adsorption, column experiments were conducted. The effects of flow rate and bed height were investigated.

\subsubsection{Effect of Feed Flow Rate}

Flow rate play an important role in evaluating the performance of de-fluoridation process. Therefore, the effect of flow rate on fluoride adsorption by AC-LS and AC-WB were performed by varying the flow rate from 5.5 to $11.5 \mathrm{ml} \mathrm{min}^{-1}$ and keeping the initial fluoride concentration and bed height constant. The effect of flow rate on breakthrough performance was shown in Fig 7A and 7B. It was observed from the figures that the adsorption efficiency was higher at lower flow rate. This can be explained by the fact that at lower flow rate, the residence time of fluoride ions on adsorbent surfaces were higher and as a result adsorption was better. As the flow rate increased, the residence time of fluoride solution on the adsorbent surfaces decreased and so the adsorption efficiency decreased.

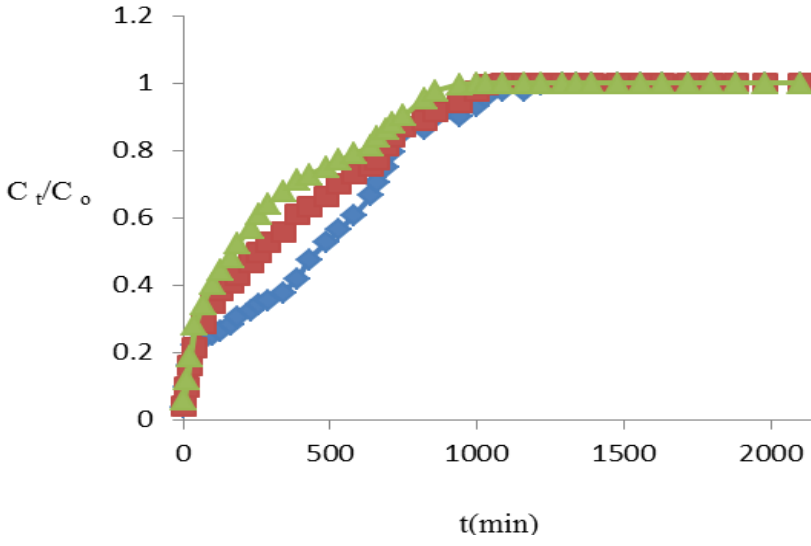

Figure7A. Effect of flow rate on breakthrough curve for adsorption of fluoride onto AC-LS

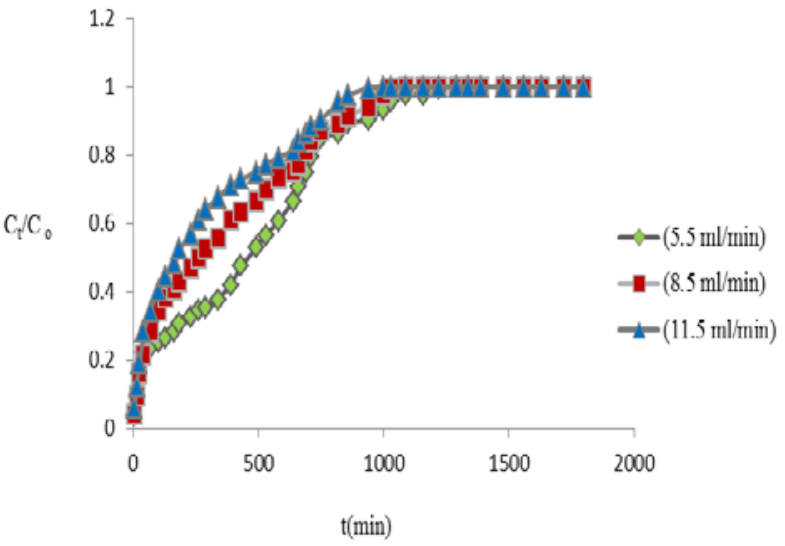

Figure7B. Effect of flow rate on breakthrough curve for adsorption of fluoride onto AC-WB

\subsubsection{Effect of Bed Height}

In order to find out the effect of bed height on the breakthrough curve, the fluoride solution having concentration $50 \mathrm{mg} \mathrm{L}^{-1}$ was passed through the column at a flow rate of $5.5 \mathrm{ml} \mathrm{min}-1$ varying the bed height. Fig. 8A and 8B represented the performance of breakthrough curves at a bed heights of $2.5 \mathrm{~cm}$, $4.5 \mathrm{~cm}$, and $6.5 \mathrm{~cm}$. From Fig. $8 \mathrm{~A}$ and $8 \mathrm{~B}$, it was observed that the breakthrough time increased with increasing bed depth from 2.5 to $6.5 \mathrm{~cm}$. As the bed height increased, the fluoride molecules had more time to contact with the adsorbent which resulted in higher removal efficiency of fluoride ions in the column. So a higher bed column resulted in decreased in the solute concentration in the effluent at the same time. 


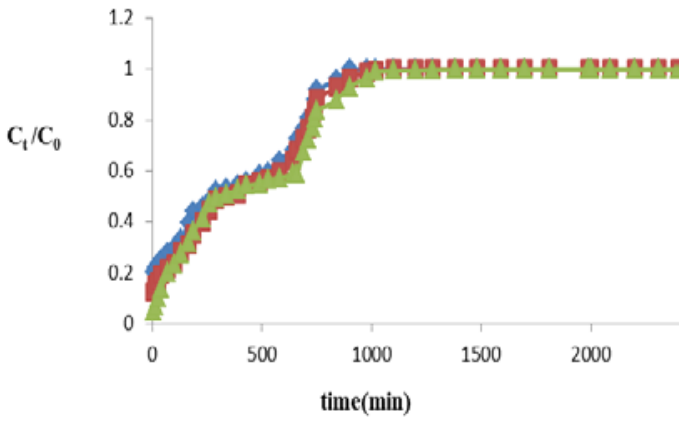

Figure8A. Effect of bed height on breakthrough curve for adsorption of fluoride onto AC-LS

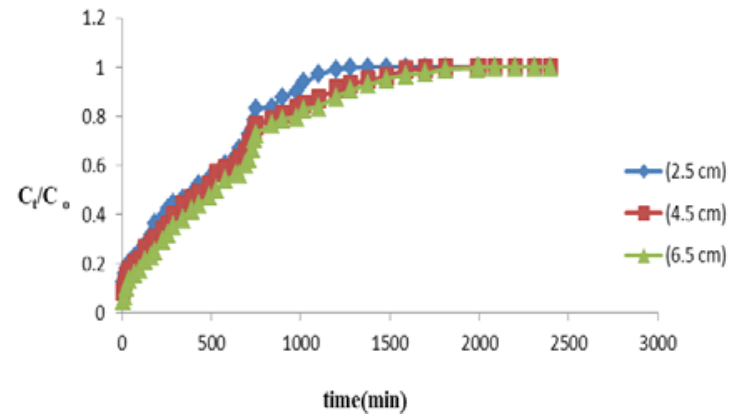

Figure8B. Effect of bed height on breakthrough curve for adsorption of fluoride onto $\mathrm{AC}-\mathrm{WB}$

\subsection{Modeling of Column Data}

\subsubsection{Thomas Model}

The Thomas rate constant $\left(k_{T h}\right)$ and bed capacity $\left(q_{0}\right)$ were calculated from the slope and intercept of the plot between $\ln \left(\frac{C_{0}}{C_{t}}-1\right)$ versus $\mathrm{t}$ at different flow rates and bed heights. The calculated values of $k_{T h}$ and $\mathrm{q}_{0}$ along with regression coefficients were presented in Table 6 . The relatively high $\mathrm{R}^{2}$ values at all the experimental condition suggested that the Thomas model [20] was suitable for describing the column study by AC-LS and AC-WB. The calculated $q_{e}$ values $\left(q_{0}\right)$ showed good agreement with the experimental $q_{e}$ values $\left(q_{e}, \exp \right)$.It implied that the suitability of the Thomas model for column design and analysis. From Table 6, it was also observed that as the flow rate increased, the bed capacity $\left(q_{0}\right)$ decreased while the $k_{T h}$ increased.

Table6. The Thomas model parameters at different conditions for the adsorption of fluoride onto AC-LS and ACWB:

\begin{tabular}{|c|c|c|c|c|c|c|c|c|}
\hline \multirow[t]{2}{*}{ Flow rate $\left(\mathrm{ml} \mathrm{min}^{-1}\right)$} & \multicolumn{2}{|c|}{$\begin{array}{c}\mathbf{k}_{\mathrm{Th}}(\mathbf{m l} \\
\left.\mathbf{m g}^{-1} \mathbf{m i n}^{-1}\right)\end{array}$} & \multicolumn{2}{|c|}{$\mathrm{q}_{0}\left(\mathrm{mg} \mathrm{g}^{-1}\right)$} & \multicolumn{2}{|c|}{$\mathrm{q}_{\mathrm{e}}, \exp \left(\mathrm{mg} \mathrm{g}^{-1}\right)$} & \multicolumn{2}{|c|}{$\mathbf{R}^{2}$} \\
\hline & AC-LS & AC-WB & AC-LS & AC-WB & AC-LS & AC-WB & AC-LS & AC-WB \\
\hline 5.5 & 0.1564 & 0.1684 & 63.456 & 61.274 & 65.987 & 68.782 & 0.976 & 0.983 \\
\hline 8.5 & 0.1876 & 0.1996 & 59.274 & 57.823 & 62.012 & 65.821 & 0.979 & 0.988 \\
\hline 11.5 & 0.2133 & 0.2283 & 57.982 & 54.382 & 59.897 & 61.284 & 0.981 & 0.993 \\
\hline Bed height & & & & & & & & \\
\hline $2.5 \mathrm{~cm}$ & 0.1176 & 0.1322 & 59.387 & 60.821 & 61.845 & 64.213 & 0.971 & 0.978 \\
\hline $4.5 \mathrm{~cm}$ & 0.1879 & 0.1889 & 62.523 & 63.256 & 63.675 & 65.985 & 0.979 & 0.984 \\
\hline $6.5 \mathrm{~cm}$ & 0.2243 & 0.2341 & 64.387 & 66.592 & 66.573 & 67.321 & 0.983 & 0.989 \\
\hline
\end{tabular}

\subsubsection{BDST Model}

The BDST model basically measures the capacity of the bed at different breakthrough values. In this model the adsorbate was adsorbed onto the adsorbent surface directly (intra particle mass transfer neglected). The BDST model parameters $K_{a}$ and $N_{0}$ were calculated respectively from the slope and intercept of the plot of $t \mathrm{Vs} Z$ at different experimental conditions which were given in Table 7 . The correlation coefficient $\left(\mathrm{R}^{2}\right)$ values were also given in Table 7 . As the values of $\mathrm{C}_{\mathrm{t}} / \mathrm{C}_{0}$ increasing, the values of $N_{0}$ increased while $K_{a}$ decreased. 
Table7. The calculated constant values of BDST model for the adsorption of fluoride onto AC-LS and AC-WB (C0 $=50 \mathrm{mg} \mathrm{l}-1, \mathrm{u}=5.5 \mathrm{ml}$ min-1)

\begin{tabular}{c|cc|cc|cc}
\hline \multirow{2}{*}{$\mathbf{C}_{\mathrm{t}} / \mathbf{C}_{\mathbf{0}}$} & \multicolumn{2}{|c|}{$\mathbf{K}_{\mathbf{a}}$} & \multicolumn{2}{c|}{$\left.\mathbf{N}_{\mathbf{0}} \mathbf{m g L}^{-1}\right)$} & \multicolumn{2}{c}{$\mathbf{R}^{2}$} \\
\cline { 2 - 7 } & AC-LS & AC-WB & AC-LS & AC-WB & AC-LS & AC-WB \\
\hline 0.3 & -287.4 & -309.1 & 132.6 & 145 & 0.983 & 0.99 \\
0.6 & -297.8 & -320.1 & 169.3 & 215 & 0.986 & 0.995 \\
0.9 & -311.5 & -348.7 & 198.5 & 297.5 & 0.991 & 0.999 \\
\hline
\end{tabular}

Table 8: Comparative adsorption capacity, isotherm of various adsorbents with AC synthesized in this study

\begin{tabular}{|c|c|c|c|}
\hline Sorbent & $\begin{array}{l}\text { Maximum adsorbent } \\
\text { capacity }\end{array}$ & Isotherm & References \\
\hline Activated Carbon (Rice straw) & $18.9 \mathrm{mg} \cdot \mathrm{g}^{-1}$ & \multirow{2}{*}{$\begin{array}{l}\text { Langmuir } \\
\text { Langmuir }\end{array}$} & {$[21]$} \\
\hline Activated Carbon (MorringaIndica) & $0.2314 \mathrm{mg} \cdot \mathrm{g}^{-1}$ & & {$[22]$} \\
\hline Activated carbon (Acacia farnesiana) & $2.622 \mathrm{mg} \cdot \mathrm{g}^{-1}$ & Freundlich & {$[23]$} \\
\hline Activated carbon (Pithacelobiumdulce) & $1.9333 \mathrm{mg} \cdot \mathrm{g}^{-1}$ & Freundlich & {$[24]$} \\
\hline Activated carbon (Arachishypogia) & $14.79 \mathrm{mg} \cdot \mathrm{g}^{-1}$ & Freundlich & [25] \\
\hline Activated carbon (Cynodondactylon) & $4.755 \mathrm{mg} \cdot \mathrm{g}^{-1}$ & Langmuir & {$[26]$} \\
\hline $\begin{array}{c}\text { Activated carbon } \\
\text { (Anacardiumoccidentale) }\end{array}$ & $1.95 \mathrm{mg} \cdot \mathrm{g}^{-1}$ & Langmuir & {$[27]$} \\
\hline Activated carbon (pecan nut shells) & $2.3 \mathrm{mg} \cdot \mathrm{g}^{-1}$ & Langmuir & [28] \\
\hline Activated Carbon(Lemon Shell) & $9.59 \mathrm{mg} \cdot \mathrm{g}^{-1}$ & Langmuir & $\begin{array}{l}\text { Present } \\
\text { Study }\end{array}$ \\
\hline Activated Carbon(Wheat Bran) & $11.84 \mathrm{mg} \cdot \mathrm{g}^{-1}$ & Langmuir & $\begin{array}{l}\text { Present } \\
\text { Study }\end{array}$ \\
\hline
\end{tabular}

\section{Conclusion}

The present work was investigated with the aim to remove fluoride present in solution using activated carbon prepared from lemon shell and wheat bran. The adsorption studies were performed at various conditions like temperature, contact time and adsorbent dose. The following conclusions may be drawn on the basis of the study:

- It was observed that the adsorption equilibrium data were well fitted to the Langmuir adsorption model rather than Freundlich adsorption model at different temperatures in case of AC-WB and AC-LS.

- The obtained experimental results showed good agreement with pseudo-second order kinetic model for both adsorbents.

- Thermodynamic parameters such as change in Gibbs free energy $\left(\Delta \mathrm{G}^{0}\right)$, enthalpy $\left(\Delta \mathrm{H}^{0}\right)$, and entropy $\left(\Delta S^{0}\right)$ were estimated. From the thermodynamic studies, the nature of the adsorption process was found as spontaneous and endothermic.

- The breakthrough curves were affected by both flow rate and bed height. As flow rate decrease, breakthrough time increased. The similar effect was observed when the bed depth was increased.

As lemon shell and wheat bran are very cheap and easily available, so these materials can be used as an effective material for the treatment of wastewater. 
Acknowledgments. This study was supported by Chemical Engineering Department, Jadavpur University, Kolkata, India and West Bengal Pollution Control Board, India. Authors are thankful for their support and service.

\section{References}

1. Lounici, H.L. ; Addour, D. ; Belhocine, H. ; Grib, S. ; Nicolas, B. Study of a new technique for fluoride removal from water, Desalination 114 (1997)241.

2. Meenakshi, R.C.; Maheshwari, J. Fluoride in drinking water and its removal. J. Hazard. Mater. 137(2006)456.

3. Saralakumari, D.; Ramakrishna Rao, P. Endemic fluorosis in the village Ralla, Anantapuramin Andhra Pradesh-An epidemiological study. Fluoride, 26(1993)177.

4. Bell, M.C. ; Ludwig T.G. The supply of fluoride to man: ingestion fromwater, in: Fluorides and Human Health, World Health Organization, Geneva. WHO Monograph Series 59(1970).

5. APHA, AWWA, WEF, Standard Methods for examination of water and waste water.22nd ed. Washington: American Public Health Association. 1360(2012).

6. Sai Sathish, R. ; Sairam, S. ; Guru Raja, V.; Nageswara Rao, G.; Janardhana, C. "Defluoridation of Water Using Zirconium Impregnated Coconut Fiber Carbon," Sep. Sci. Technol., 43(2008)3676.

7. Jun T.; Arumugam S.D.; Latip N.H.A .; Abdulla A. M.; Latif P. A. Effect of Activation Temperature and Heating Duration on Physical Characteristics of Activated Carbon Prepared from Agriculture Waste, Environment Asia 3(2010) 143.

8. Sricharoenchaikul Viboon.; Pechyen Chiravoot.; Aht-ong Duangdao. ; Atong Duangduen. Preparation and Characterization of Activated Carbon from the Pyrolysis of Physic Nut (Jatropha curcas L.) Waste, Energy Fuels, 22(2008)31.

9. Evbuomwari B.O. ; Agbede A.M. ; Atuka M.M. A Comparative Study of the physico-chemical properties of Activated Carbon from oil palm waste, International Journal of Science and Engineering Investigations, $2(2013) 75$.

10. Rodriguez-Reinoso F. ; Lopez-Gonzalez J. ; Berenguer C. Activated carbons from almond shells -1:Preparation and characterization by nitrogen adsorption, Carbon, 20(1982)513.

11. Chakrapani, C. ; Suresh Babu, Ch.; Vani. K.N.K.; Somasekhara Rao, K. "Adsorption Kinetics for the Removal of Fluoride from Aqueous Solution by Activated Carbon Adsorbents Derived from the Peels of Selected Citrus Fruits," E-Journal of Chemistry, 7(2010)419.

12. Malkoc, E.; Nuhoglu, Y. Fixed Bed Studies for the Sorption of Chromium (iv) on Tea Factory waste, Chem.Eng. Sci., 16(2006)4363.

13. Otero, M.; Garcı'a, A.I.; Mora'n, A. Application in fixed-bed systems of adsorbents obtained from sewage sludge and discarded tires. Dyes EYPigm., 72(2007)47.

14. Hall, K.R.; Eagleton, L.C.; Acrivos, A.; Vermeulen, T. Pore and Solid-diffusion kinetics in fixed-bed adsorption under constant pattern conditions. Ind. Eng. Chem. Fundament, 5(1966) 212

15. Lee, V.K.; Porter, J.F.; McKay, G. Development of fixed-bed adsorber correlation models.Ind. Eng. Chem. Res., $39(2000) 2427$.

16. Freundlich, H. Uber die adsorption in losungen (adsorption in solution), Z.Phys. Chem. 57 (1906) 384.

17. Langmuir, I. The adsorption of gases on plane surfaces of glass, mica andplatinum, J. Am. Chem. Soc. 40 (1918) 1361.

18. Ghorai, S.K.; Pant, K. Equilibrium, kinetics and breakthrough studies for adsorption of fluoride on activated alumina, Sep. Purif. Technol. 42(2005) 265.

19. Swaina SK.; Patnaikb T. ; Singha VK. ; Jhaa U. ; Patelc RK. ; Dey RK. Kinetics, equilibrium and thermodynamic aspects of removal of fluoride from drinking water using meso-structured zirconium phosphate. Chem Eng J. 171(2011)1218.

20. Han, R.P.; Wang, Y.; Zou, W.; Wang, Y.F.; Shi, J. Comparison of linear and nonlinear analysis in estimating the Thomas model parameters for methylene blue adsorption onto natural zeolite in fixed-bed column. J. Hazard. Mater., 145(2007)331. 
21. Daifullah, A.A.; Yakout, S.M.; Elreefy, S.A. Adsorption of fluoride in aqueous solutions using $\mathrm{KMnO}_{4}$-modified activated carbon derived from steam pyrolysis of rice straw. J. Hazard. Mater. 147(2007)633.

22.Karthikeyan, G.; Siva Ilango, S. Fluoride sorption using Morringa Indica-based activated carbon.Iran. J. Enviton. Health Sci. Eng. 4(2007)21.

23. Hanumantharao, Y.; Kishore, M.; Ravindhranath, K. Preparation and development of adsorbent carbon from Acaciafarnesiana for defluoridation. Int. J. Plant Anim. Environ. Sci. 1(2011)209.

24. Emmanuel, K.A.; Ramaraju, K.A.; Rambabu, G.; Veerabhadra Rao, A. Removal of fluoride from drinking water with activated carbons prepared from HNO3 activation-A comparative study. Rasayan J. Chem. 1(2008)802.

25. Alagumuthu, G.; Rajan, M. Kinetic and equilibrium studies on fluoride removal by zirconium (IV): Impregnated groundnut shell carbon. Hem. Ind. 64(2010) 295.

26. Alagumuthu, G.; Veeraputhiran, V.; Venkataraman, R. Fluoride sorption using Cynodondactylon based activated carbon. Hem. Ind. 65(2011)23.

27. Alagumuthu, G.; Rajan, M. Equilibrium and kinetics of adsorption of fluoride onto zirconium impregnated cashew nut shell carbon. Chem. Eng. J. 158(2010)451.

28. Hernández-Montoya, V.; Ramírez-Montoya, L.A.; Bonilla-Petriciolet, A.; Montes-Morán, M.A. Optimizing the removal of fluoride from water using new carbons obtained by modification of nut shell with a calcium solution from egg shell. Biochem. Eng. J. 62(2012)1. 